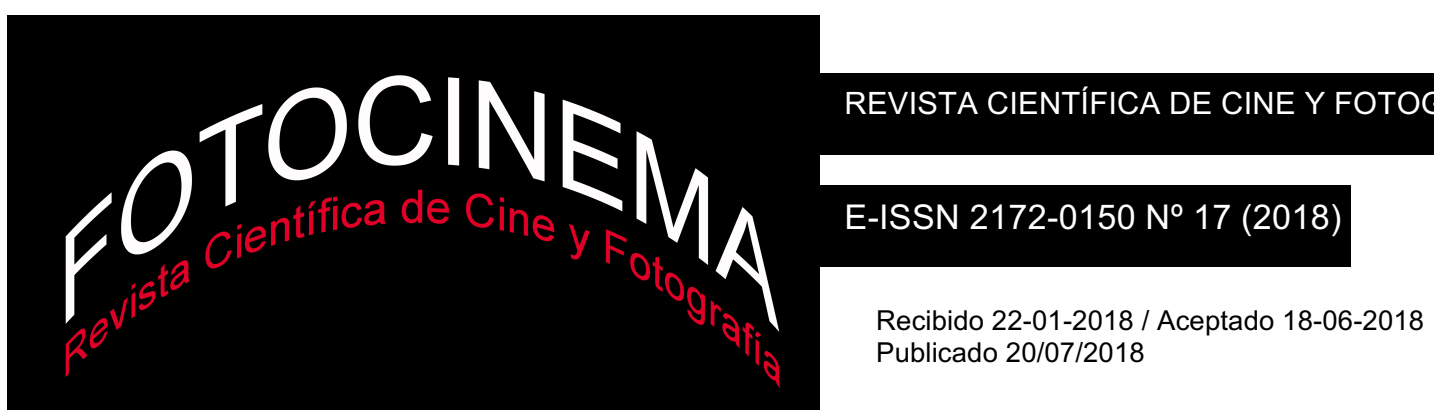

\title{
El uso del travelling como marca del estilo de Wes Anderson: análisis de Academia Rushmore (1998), Los Tenenbaums: una familia de genios (2001) y El Gran Hotel Budapest (2014)
}

\section{The use of travelling as a mark of Wes Anderson's style: analysis of Rushmore (1998), The Royal Tenenbaums (2001) and The Grand Budapest Hotel (2014)}

\author{
Tomás Atarama-Rojas \\ Universidad de Piura, Perú \\ tomas.atarama@udep.pe
}

\section{Fiorella Vílchez Chiroque \\ Universidad de Piura, Perú \\ fiorella.vilchezchiroque@gmail.com}

\section{Resumen:}

Wes Anderson es un director de cine reconocido a nivel mundial por el particular estilo que le imprime a cada una de sus películas. En este estudio analizamos la importancia del uso de los travellings en la construcción del estilo personal de dicho director, tomando como objeto de estudio tres películas de su amplia filmografía, Academia Rushmore (1998), Los Tenenbaums: Una familia de genios (2001) y El Gran Hotel Budapest (2014). Para alcanzar este objetivo se realizará un análisis del uso de los travellings y su aporte al desarrollo de las historias de los filmes. Los resultados señalan que este movimiento de cámara es utilizado por el estadounidense para resaltar el encuentro que tienen los protagonistas consigo mismos y darle continuidad a la historia tras la maduración sufrida por estos a lo largo de la película.

\begin{abstract}
:
Wes Anderson is a film director recognized worldwide for the particular style he gives to each of his films. In this study we will analyze the importance of the use of travellings in the construction of this director's personal style, taking as an object of study three films from his extensive filmography, Rushmore (1998), The Royal Tenenbaums (2001) and The Grand Budapest Hotel (2014). To achieve this goal, we will make an analysis of the use of the travellings and their contribution to the development of the films stories. The results suggest that this camera movement is used by this American director to highlight the encounter that the protagonists have themselves and to give continuity to the story through the maturation suffered by them throughout the film.
\end{abstract}

Palabras clave:

Travelling; estilo de autor; Wes Anderson; movimientos de cámara; cine

Keywords:

Travelling; author style; Wes Anderson; camera movements; cinema 


\section{Introducción}

En el campo de la comunicación audiovisual, el estilo que los directores de cine imprimen a sus películas es lo que les diferencia de los demás autores y lo que los hace reconocidos ante el público. Así, "toda obra tiene un autor y esta no sería posible sin él [...]. La función de autor establece una caracterización propia de un cierto modo de discurso" (Martínez, Sánchez y Segura, 2012, pp. 184-185). Según Rodríguez de Austria (2015), la intencionalidad del autor se puede estudiar a través de la composición y la expresión de la figura misma. Cada película lleva un sello de autor que la diferencia de las demás realizadas por otros directores y, en este sentido, Wes Anderson es un director muy reconocido mundialmente por el peculiar estilo que tienen sus obras. "Este cineasta crea meticulosamente sus imágenes visuales para la pantalla de modo que el público reconozca la intención de su trabajo como director, un estilo de dirección distinto que le ha ganado fama y notoriedad en los últimos años" (Vreeland, 2015, p. 36).

En este trabajo, a diferencia de otros ya realizados sobre el estilo característico de este director, como los estudios de Boschi y McNelis (2012), Herzog (2014), Vreeland (2015) y Ráez (2016); pondremos énfasis en la importancia que tienen los travellings como técnica cinematográfica utilizada por este autor para crear el sello que lo distingue y que hace que los espectadores se familiaricen con su manera de hacer películas; en especial durante el desenlace de la historia, en el que el travelling es usado para mostrar el encuentro que tienen los personajes principales consigo mismos y el cambio que ha habido en ellos y en los personajes que los rodean.

Para esto, se ha decidido escoger tres películas de la filmografía de Anderson: Academia Rushmore (Rushmore, 1998), Los Tenenbaums: Una familia de genios (The Royal Tenenbaums, 2001) y El Gran Hotel Budapest (The Grand Budapest Hotel, 2014). Nuestra elección se basa en que estos filmes figuran en la lista de la BBC de las 100 mejores películas del siglo en el que fueron estrenadas, realizada por críticos de reconocidas revistas, periódicos y universidades de todo el mundo; además, han sido nominadas a reconocidos premios como el Oscar y los Globo de Oro, asimismo, son las tres películas 
más representativas del director en cada década de su trayectoria artística según el rating de IMDb.

En el cine resulta interesante explorar los elementos del estilo personal de los autores, porque como señala Galindo:

Hay películas en las que la personalidad del director puede ser rastreada e identificada en cada una de sus obras en forma de tópicos temáticos, motivos formales o recursos estilísticos. Lo relevante de estos filmes son las huellas que permiten señalarlas como testimonios de una visión, de una personalidad individual (Galindo, 2015, p. 53).

Visto esto, la pregunta de investigación que guía este trabajo es ¿̇cuál es el aporte del travelling al estilo de Wes Anderson en la creación de mundos fantásticos? Ante esta interrogante, sostenemos la hipótesis de que el uso de los travellings en las películas de Wes Anderson contribuye al sello personal que distingue al director estadounidense, ya que usa estos movimientos de cámara para darle continuidad a la ficción y explorar el mundo interior de los personajes.

Finalmente, la metodología que usaremos para el estudio de los casos será el análisis del uso de los travellings y su aporte al desarrollo de las historias de los filmes antes mencionados. Se tomarán como objeto de análisis escenas de los últimos treinta minutos de las películas donde se aprecien estos movimientos de cámara para observar cuál es su importancia dentro de la acción y cómo influyen en la construcción del sello personal de Wes Anderson.

\section{Marco teórico}

\subsection{El estilo personal en las ficciones cinematográficas}

Por medio de la utilización de los recursos fílmicos, los cineastas pueden lograr un estilo propio que los caracterice. Bordwell (1997) define el estilo cinematográfico como el uso sistemático y significativo de los elementos formales de la puesta en escena. Ante esto, Cortés-Selva (2013) afirma que la “teoría de la práctica cinematográfica es el modo más preciso para 
determinar los elementos que dependen de cada autor cinematográfico de modo individual, lo que posibilita el análisis exhaustivo del estilo de los creadores que participan en una producción cinematográfica” (p. 495). Así, Cortés-Selva define la práctica cinematográfica a partir de las opciones por las que se decantan los creadores cinematográficos y que están sometidas a limitaciones históricas, presupuestarias y narrativas, que sirven para crear una historia que refleje la evolución de su estilo cinematográfico.

Asimismo, Bordwell y Thompson (2009) señalan que el estilo distintivo de los cineastas se plasma en su forma de utilizar las diferentes técnicas del cine en su filmografía, esto hace que los espectadores se familiaricen con su manera de hacer películas, y marca una diferencia en cómo ellos perciben y responden ante estas en comparación con los filmes de otros directores.

Para Vreeland (2015), "el estilo de dirección trasciende el arte de la creación de películas en sí mismo, ya que muchas veces, se convierte en un rasgo generacional definitorio o en una forma de vida" (p. 35). De esta manera la personalidad del autor, como señala Galindo (2015), se visualiza en sus películas. "Existen signos distintivos de la obra de un determinado autor, que establecen cierta continuidad y homogeneidad en su producción” (Martínez, Sánchez y Segura, 2012, p. 186). Por ejemplo, en el caso de Wes Anderson, el escenario que presenta continuamente en sus películas es claramente suyo, fácilmente identificable por los elementos del lenguaje cinematográfico que utiliza, unos de estos elementos son las exuberantes paletas de colores predominantemente amarillas y la simetría (Herzog, 2014).

Después de entender que el estilo personal lo constituyen variados elementos dentro del entorno de la ficción cinematográfica, vamos a explorar estos elementos según la visión de diferentes autores. En primer lugar, en cuanto al guion como diferenciador del estilo personal, la práctica de escritura de guiones que usa el escritor al desarrollar y componer la historia dramática le ayuda a externalizar el contenido de la historia de tal manera que es posible presentarlo y ejecutarlo cinematográficamente para el espectador (Koivumäki, 2016). Al considerar el guion como un plan para una presentación cinematográfica, es vital que el guionista estudie y analice 
películas para comprender la narración visual y adquirir nuevos conocimientos sobre los medios narrativos y dramatúrgicos, mejorando así sus habilidades de escritura (Koivumäki, 2014).

En segundo lugar, se puede hablar de estilo personal a partir del trabajo de los directores con los actores y los elementos configuradores de la puesta en escena con los que se pone en manifiesto su estilo cinematográfico, ya que según Cortés-Selva y Martínez-Carmona (2013) estos son los dos ámbitos más importantes que definen la labor de un director de cine.

En tercer lugar, tenemos que la puesta en escena es, para Bordwell y Thompson (1995), la técnica cinematográfica con la que el público puede reconocer más fácilmente el estilo de un autor. A través de la puesta en escena el director puede controlar lo que aparece en la imagen fílmica, para ello hace uso de los decorados, la iluminación, el vestuario y el comportamiento de los personajes. Con ello el cineasta logra guiar la atención del espectador por la pantalla, dirige la percepción de la acción que está transcurriendo y pone en relieve ciertas partes de la historia. "En el cine, las pistas visuales estáticas referentes a «cuándo mirar a dónde» se refuerzan o socavan mediante el movimiento de los personajes o de la cámara, mediante la banda de sonido y el montaje, y mediante la forma total del filme" (p. 184).

En cuarto lugar, podemos observar que autores como Roda (2012) destacan en la puesta en escena elementos como "el encuadre, la localización de personajes, la composición de las escenas y la iluminación que nos permiten realizar una lectura cinematográfica de las obras de los directores porque visualmente se estructuran como planos pensados a través del lenguaje del cine” (p. 98). Del mismo modo, la música, es otro recurso importante a tener en cuenta, pero que ha tendido a ocultarse en las sombras, diferenciándose de otros elementos de la narración, el estilo visual y la praxis de director (Boschi y McNelis, 2012).

El director de cine tiene a su disposición diversas herramientas del lenguaje cinematográfico para evocar emociones en el espectador. Una de las herramientas puede ser el uso de la "espera", la cual supera el dominio del 
suspense y entra en el terreno de lo surrealista, un concepto que a veces llega a confundirse con la presencia de lo fantástico en el entorno cotidiano y que era muy bien manejado por directores como Hitchcock (Jackson-Martin, 2015).

Por otro lado, el director plasma en sus películas su visión personal del mundo con un estilo que lo distingue de los demás (Ráez, 2016). En el cine postmoderno, como indican Arráez y Pascual (2014), los cineastas utilizan la estética y la narrativa para contar historias sobre el mundo donde están inmersos. Es así como añaden a estas realidades su sello y las mezclan con la ficción, mostrando una postura respecto a su entorno.

\subsection{El uso del travelling en el estilo de autor}

El valor narrativo de los movimientos de cámara según Bordwell y Thompson (1995) radica en que desempeñan varias funciones, todas ellas de apoyo directo a la historia. En primer lugar, cuando la cámara se mueve por su cuenta crea suspenso o proporciona información de aquello que ignoran los personajes. De este modo, los movimientos de cámara ayudan a plasmar una narración en cierto modo ilimitada. También sirve para realizar patrones con significación narrativa y de esta manera vincular a los personajes con detalles de su entorno. De la misma forma, aumentan la información sobre el espacio de la imagen, como objetos o figuras nuevas; asimismo, cuando la cámara se aleja de los personajes se usa para revelar algo de importancia para la narración.

En general, para estos dos autores un movimiento de cámara puede crear efectos significativos para la continuación de la acción, pero siempre atendiendo a las necesidades narrativas de la película. "Un rápido travelling hacia adelante dirigido a un objeto importante o un lento plano de grúa desde las figuras de un paisaje pueden subrayar fragmentos clave de la información de la historia” (Bordwell y Thompson, 1995, p. 226).

El cine, en sus comienzos, había tomado muchas características propias del teatro, sin embargo, con el correr del tiempo, los directores aprendieron a utilizar técnicas propias del lenguaje cinematográfico, como mover la cámara 
(travelling) o inclinarla en ángulo picado y contrapicado (López, 2012). Es así que hoy en día, como señala Rodríguez (2014), el dominio del espacio y del escenario de la historia es muy importante en el cine, tanto para que el público no se desoriente durante la acción como para enriquecer el sentido narrativo de la historia mostrada. El director debe saber coordinar los movimientos de cámara, los actores, el montaje y los diferentes recursos narrativos con los que cuenta, para que todos sumen a la realización de la historia.

En este sentido la planificación, dicen Rodríguez, Gonzálvez y Caldevilla (2016), da lugar a la creación de escenarios, el ritmo, el montaje, la utilización de la cámara, su posición, su encuadre, sus movimientos, su óptica. Esto sirve para adentrar al espectador en la historia que estamos contando y a su vez reforzar el trabajo de dirección y el sello de autor.

Para estos mismos autores:

El movimiento de la cámara constante ayuda a ofrecer claridad en la composición geográfica del espacio de la acción, del mismo modo que activar la profundidad de campo enfocando y desenfocando elementos en el cuadro aumenta la profundidad sugerida, empujando al espectador al espacio y a la acción, acercando la percepción de sus imágenes, de sus filmes en definitiva, a la realidad. La cámara se mueve, se abre paso por el espacio de la acción, acompaña a los personajes, descubre y describe detalles, siempre en beneficio de la intriga, combinación perfecta del 'cómo' al 'qué' (Rodríguez et al, 2016, pp. 23, 24).

Al igual que los autores anteriores, Mercado (2011) coincide en que el travelling sirve para adentrar al espectador en la historia, ya que la cámara al moverse físicamente, manteniendo constante la longitud focal, hace que el espectador tenga la sensación de que es él el que se mueve hacia adelante o hacia atrás con respecto al encuadre. Asimismo, dice que preferir el uso de los travellings a realizar un corte hace que se resalte la importancia del momento en la historia, por lo que este recurso se debe emplear con moderación y reservar para momentos en que el espectador deba conectar intensamente con una situación o un personaje. 
Bordwell y Thompson (2009) concuerdan con lo ya antes mencionado y afirman que el movimiento de cámara es utilizado por los directores para que el espectador preste atención a la acción que ocurre en la pantalla, pero también ayuda a fortalecer, respaldar y enriquecer la forma narrativa de la película.

En el caso de nuestra investigación, Wes Anderson recurre a movimientos limpios y ordenados, tanto de la cámara como de los personajes, donde estos últimos se desplazan para cumplir un objetivo propuesto por la acción narrativa (Ráez, 2016). "En el cine de Anderson no se encuentran movimientos agitados con la cámara en mano, ni trávelin acelerados, ni paneos violentos, ni desplazamientos dubitativos. El orden simétrico de la composición visual establece la funcionalidad de los movimientos” (p. 27).

Ferreras y Vergilio (2008) también opinan que el uso del travelling sirve para hacer que el espectador se sienta parte de los hechos que ocurren en el relato. Los autores señalan que en específico Wes Anderson usa movimientos de cámara muy cortos en sus películas para acompañar a sus personajes cuando se sientan, se levantan o se desplazan lateralmente dentro de un espacio determinado; todo esto para colocar al público en la "piel de los personajes" y hacer como si ellos "movieran” el plano. Ferreras y Vergilio (2008) sostienen que "los movimientos de cámara del director a menudo tienen que ver con el punto de vista del personaje de la película o con su estado emocional y suelen tener un marcado carácter subjetivo" (pp. 271272). Mediante los movimientos de cámara, este director explora diferentes opciones para expresar lo que quiere transmitir a su audiencia, y de esta manera guiarla a través de la acción que transcurre a lo largo de sus filmes.

\section{Material y Metodología}

\subsection{Material}

En este estudio se ha escogido analizar las películas del director de cine estadounidense Wes Anderson, ya que es uno de los más reconocidos por su peculiar estilo dentro del séptimo arte. Anderson utiliza una serie de recursos 
en todas sus obras que las hacen fácilmente identificables del resto, como el uso del color, la simetría en cada uno de sus planos, el humor de sus personajes, la división de sus películas en capítulos, los elementos recurrentes como los libros, los decorados de la escenografía y, sobre todo, el uso de los travellings.

Como muestra para el desarrollo de la metodología se han seleccionado tres de las películas de la filmografía de este director: Academia Rushmore, Los Tenenbaums: Una familia de genios y El Gran Hotel Budapest. En estas películas Anderson usa los travellings para seguir el desarrollo de las acciones de sus personajes, donde se puede observar la sincronía visual de estos en el paisaje con un ritmo pauteado, permitiendo que el espectador se adentre y se centre en lo que el director quiere mostrar en cada escena.

El primer filme, Academia Rushmore, cuenta las aventuras y desventuras de Max Fischer, un entusiasta estudiante de esta escuela que, aunque miembro $\mathrm{y}$ fundador de decenas de clubs, no es precisamente brillante y vive con la constante amenaza de la expulsión. Max tiene su corazón dividido entre el profundo afecto que tiene hacia su escuela y el ferviente amor hacia una profesora. Aun así, luchará férreamente por conseguir el amor de su profesora, aunque para ello tenga que competir con su mejor amigo, el Sr. Blume.

Esta película consagró a su director como una figura ineludible del cine americano y es considerada uno de los grandes filmes del siglo XX según la lista sobre las 100 mejores comedias de todos los tiempos realizada por la BBC Culture (2017), donde Academia Rushmore ocupa el puesto 94. Asimismo, tiene una puntuación de 7,7/10 de rating en el portal de IMDb, y fue nominada a un Globo de Oro.

La segunda película seleccionada, Los Tenenbaums: Una familia de genios, trata sobre Royal Tenenbaum, quien regresa con su familia disfuncional tras 17 años de separación fingiendo un grave caso de cáncer de estómago, argumentando que le quedan solo seis semanas de vida, con la intención de recuperar a sus tres hijos y a su esposa, que está a punto de volver a casarse. Esta cinta es importante en la filmografía de Anderson pues ocupa el puesto 
68 en la lista de las 100 mejores películas del siglo XXI publicada por la BBC Culture (2016). Además, ha sido nominada al Oscar, al Globo de Oro y al BAFTA. Del mismo modo, tiene una puntuación de 7,6/10 de rating en el portal de IMDb.

La última obra que analizaremos será El Gran Hotel Budapest, que narra las aventuras de Gustave H., el conserje de un famoso hotel europeo del período de entreguerras, y de Zero Moustafa, un botones que se convierte en su amigo más leal. Esta película también se encuentra en la lista de las 100 mejores películas del siglo XXI publicada por la BBC Culture (2016), ocupando el puesto 21. Y al igual que la anterior película también fue nominada al Oscar, al Globo de Oro y al BAFTA. En el rating de IMDb tiene un puntaje de 8,1/10.

El criterio principal de elección de estos tres filmes para el estudio es que figuran en las listas de la BBC Culture como películas sobresalientes en los siglos en que han sido estrenadas. Estas listas fueron elaboradas a través de la votación de críticos especializados de todo el mundo de reconocidas revistas y portales web como Variety, IndieWire, Fandango, Rolling Stone, The Hollywood Reporter, Vanity Fair; diarios como La Nación de Argentina, The Guardian, Los Angeles Times, The Telegraph, El Mercurio de Chile, The Washington Post, USA Today; universidades como las de Glasgow, de New York, de Londres y la de Tokio; y festivales de cine como el Toronto Film Festival y el African Film Festival Inc. También, han sido nominadas a premios de reconocimiento internacional como los Oscar, el Globo de Oro y el BAFTA. Asimismo, estas tres películas son las más representativas del director en cada década de su trayectoria artística según el rating de IMDb.

\subsection{Metodología}

Para comenzar haremos una aproximación al uso de los travellings de modo cuantitativo para saber cuánto usa Wes Anderson estos movimientos de cámara en sus películas mediante su conteo en cada acto en que se componen los filmes: planteamiento, desarrollo y resolución o desenlace; y su duración aproximada, todo esto organizado en un cuadro de doble entrada. 
Asimismo, en este trabajo se utilizará una metodología cualitativa con la cual nos aproximaremos al estudio de las tres películas en un análisis en el que convergen elementos estéticos propios del lenguaje audiovisual y elementos narrativos propios de la historia, centrándonos en el uso del travelling. Para esto haremos una comparación entre las secuencias en donde se utilizan los travellings con las demás secuencias de las películas para verificar qué es lo que estos aportan y destacan. Se describirá la escena, cómo es que se introduce el travelling en esta y en qué es lo que contribuye en el filme.

Para ello se ha escogido analizar los últimos treinta minutos de las tres películas anteriormente mencionadas en el trabajo, ya que según la Poética de Aristóteles (1450b, 25), quien dividió a los relatos en tres momentos: el principio, el medio y el fin, es en el último de estos en donde se muestra el principio del cambio del protagonista hasta el término de la historia ${ }^{1}$. El personaje principal llega al punto álgido de la historia y descubre la moraleja del relato. Junto con él, la audiencia también descubre al fin la premisa de la narración. Aristóteles lo definía como la purificación del público a través de la piedad y el terror.

Por su parte, Seger (1991) señala que la composición dramática, casi desde los comienzos del drama, ha tendido siempre hacia la estructura en tres actos: principio, medio y final; o también llamados planteamiento, desarrollo y resolución ${ }^{2}$. Para esta autora el final de la historia es el momento en que "se resuelve el problema, se contesta la cuestión central, se acaba la tensión y se arregla todo" (p. 54). Por su parte McKee (2009) dice que "hay un reverenciado axioma en Hollywood que nos avisa: 'Toda película trata de lo que se ven en sus últimos veinte minutos” (p. 139).

La noción del uso de los travellings será el eje conceptual que permitirá analizar las películas de Anderson. Por ello, pretendemos establecer los patrones de movimiento de cámara y ligarlos al sentido general de sus

${ }^{1}$ A este principio, medio y fin, Aristóteles no los llama tres actos, sino que solamente los considera como tres partes de la acción dramática.

${ }^{2}$ La estructura de tres actos es la más extendida y utilizada por los guionistas para dar un orden y estructura que ayude a la comprensión de las historias. 
películas, teniendo como punto central la singularidad de su obra personal, ya que como planteamos en la hipótesis, el uso de los travellings en las películas de Wes Anderson contribuyen al sello personal que distingue al director para darle continuidad a la ficción y explorar el mundo interior de los personajes.

\section{Los travellings, la continuidad en la ficción y la inmersión del espectador durante la transformación de los personajes}

Comenzaremos con el análisis cuantitativo de los filmes seleccionados, para ello presentaremos a continuación un cuadro de doble entrada dividido en los tres actos en que constan las películas, junto con el número de travellings en cada uno de estos; así como, una aproximación en segundos de la duración de los travellings en cada acto.

Tabla 1: Aproximación cuantitativa al uso de los travellings en Wes Anderson

\begin{tabular}{|c|c|c|c|c|}
\hline Películas & Travellings & Planteamiento & Desarrollo & Descenlace \\
\hline $\begin{array}{c}\text { Academia } \\
\text { Rushmore }\end{array}$ & Número & 7 & 54 & 21 \\
\cline { 2 - 5 } & Duración & $4-10 \mathrm{~s}$ & $3-12 \mathrm{~s}$ & $3-13 \mathrm{~s}$ \\
\hline $\begin{array}{c}\text { Los Tenenbaums: } \\
\text { Una familia de } \\
\text { genios }\end{array}$ & Número & 20 & 25 & 24 \\
\cline { 2 - 5 } & Duración & $3-6 \mathrm{~s}$ & $2-30 \mathrm{~s}$ & $2-15 \mathrm{~s}$ \\
\hline $\begin{array}{c}\text { El Gran Hotel } \\
\text { Budapest }\end{array}$ & Número & 14 & 20 & 7 \\
\cline { 2 - 5 } & Duración & $2-6 \mathrm{~s}$ & $2-8 \mathrm{~s}$ & $2-6 \mathrm{~s}$ \\
\hline
\end{tabular}

Fuente: Elaboración propia.

A partir de esta primera aproximación cuantitativa, se puede afirmar que Wes Anderson usa de modo recurrente los travellings en las películas analizadas, por que lo que este movimiento de cámara es un rasgo característico de su estilo personal. No existe una constante respecto al tiempo de duración de este recurso, pero sí queda claro que está presente en toda la historia. Para vincular el uso de este recurso audiovisual con el sentido narrativo de las películas analizadas, se realiza una aproximación 
cualitativa que busca explorar cómo es usado el travelling en los momentos claves del desenlace de las historias. Así, se explorará si el travelling es capaz de destacar el cambio que ha surgido en el personaje principal y en su entorno.

Cada uno de los análisis comienza con una presentación específica de la secuencia, luego viene el análisis de cada secuencia a través de los diferentes elementos del lenguaje audiovisual que ponen de relieve el uso del travelling. Finalmente, se realiza una interpretación del aporte del movimiento de cámara a la historia contada, para esto, se valorará sus contribuciones en función de la globalidad de la historia, de su continuidad y de cómo adentra al espectador en la evolución del personaje principal.

\subsection{Academia Rushmore y el uso del travelling para descubrir el encuentro del protagonista consigo mismo}

Para analizar el aporte del travelling en la continuidad de la historia y en la inmersión en el mundo interior del personaje principal, se ha seleccionado una secuencia del minuto 69 de la película Academia Rushmore que se presentará a continuación.

Max Fisher se encuentra junto a Dirk Calloway, su antiguo amigo y seguidor de Rushmore, con quien se había peleado debido a un comentario realizado por Max sobre él y la madre de Dirk. El chico vuela una cometa, mientras que Max está en cuclillas a su costado en un plano general. Luego hay un primer plano de Max y este le pide perdón a Dirk por la mentira que dijo sobre su madre. Hay un primer plano de Dirk y este lo perdona y también se disculpa por no haberlo ayudado cuando lo golpearon. Después hay un plano conjunto de Max y Dirk, ellos ven volando un avión a control remoto. Aparece Margaret, la compañera de colegio de Max, este ve el plan de vuelo hecho por ella. Hay un plano conjunto de Max y Margaret, ellos comienzan a hablar sobre el proyecto de ciencias de Margaret y ella le dice que fue un imbécil con ella, a lo que Max se disculpa. Margaret termina diciendo que fue bueno verlo de todas maneras. 
Luego, hay un plano conjunto de Dirk y Max. Dirk le pregunta a Max si quiere remontar la cometa y él acepta. Hay un travelling de acercamiento (F1) hacia el rostro de Max, quien al ver volar la cometa le dice a Dirk que tome nota. Él lo mira asombrado y entusiasmado de que Max vuelva a querer emprender un nuevo proyecto. Max dice: "Posibles candidatos para la Sociedad de Barriletes”, y le da una serie de nombres, incluida Margaret. Hay un travelling de alejamiento (F2) mientras Max le dicta los nombres a Dick y comienza a sonar la música extradiegética.

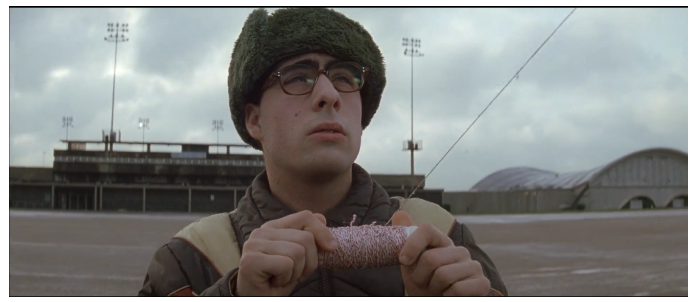

F1: Travelling de acercamiento.

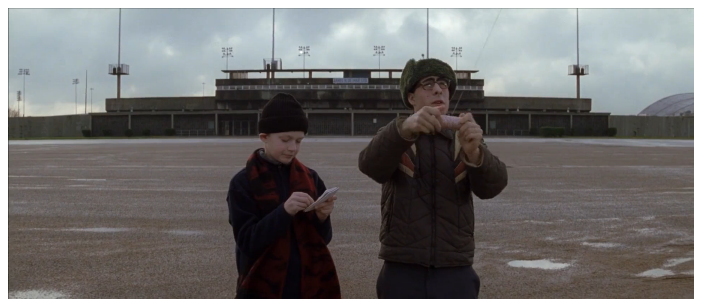

F2: Travelling de alejamiento.

En esta escena el travelling de acercamiento nos conduce a apreciar el cambio de actitud que ha tomado el protagonista en relación con su vida. Gracias a las conversaciones que ha tenido anteriormente con sus dos amigos y a sus respectivas reconciliaciones ahora vuelve a recobrar su entusiasmo y a querer emprender nuevos proyectos.

Por otro lado, el travelling de alejamiento ha servido para reforzar el encuentro de Max con esta nueva motivación para seguir haciendo lo que le gusta y rompe con lo que lo mantenía atado a la profesora Cross y a Rushmore, comienza otra etapa en su vida en su nuevo colegio. El travelling ayuda a que el espectador sienta el encuentro que Max ha tenido consigo mismo, y a que haya una continuidad en la historia tras el cambio que ha sufrido el protagonista.

La otra escena que analizaremos es la del minuto 73, en ella el señor Blume va a la barbería del papá de Max. Hay un primer plano de Blume delante del local. Él ha llegado para hablar con Max y reconciliarse.

Blume se encuentra descuidado, desarreglado y decaído tras la ruptura con la profesora Cross. Max llega y le entrega una caja, hay un plano contraplano, dentro de la caja hay dos medallas que ganó Max en su paso por Rushmore: 
una por asistencia perfecta y otra por puntualidad. El chico le pide a Blume que escoja la que más le guste y le dice que la otra la usaría él. Así sellan los dos su reconciliación y marcan el fortalecimiento de su amistad. Blume elige la medalla de puntualidad, hay un plano conjunto, los dos se colocan sus medallas y Blume le agradece a Max. Él lo invita a pasar a dentro de la barbería de su padre.

Hay un corte y Max una vez dentro los dos, los presenta, revelándole la verdad de la profesión de su padre, mostrándose tal cual es, sin aparentar nada esta vez. Blume se da cuenta del engaño de Max al decirle anteriormente que su padre era neurocirugano, pero se alegra de conocer la verdad ahora. El señor Fisher le corta el pelo y lo afeita.

Luego de esto Max y Blume salen de la barbería y hay un travelling de acompañamiento (F3) mientras los dos caminan conversando sobre cuánto dinero tiene Blume, este le pregunta porqué es que quiere saber eso, a lo que Max le contesta: "Porque lo vamos a necesitar todo".

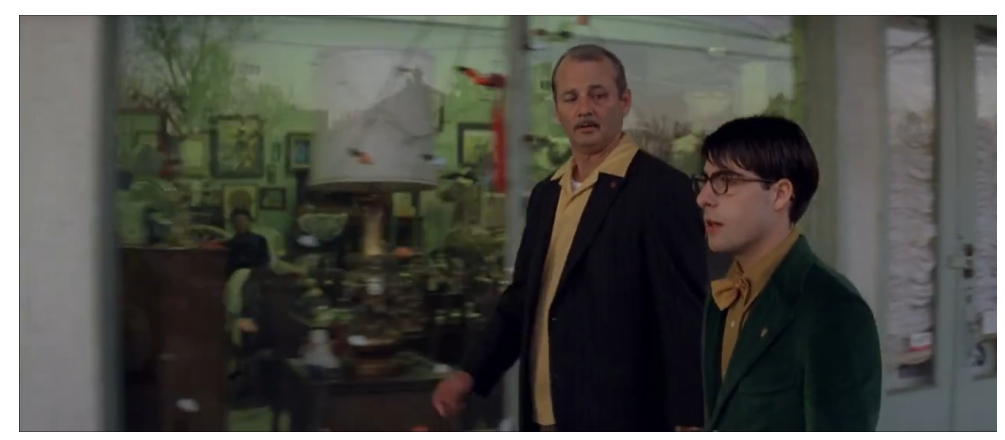

F3: Travelling de acompañamiento.

Con este travelling de acompañamiento, Wes Anderson sella la reconciliación entre Max y Blume y da pie a su renovada amistad, una más sincera que la anterior. Da relevancia al cambio que ya vimos en la secuencia anterior en la que se reconcilió con su amigo y fiel seguidor Dirk; y nos inmiscuye más en la evolución que está teniendo el protagonista en la historia, en su maduración. 


\subsection{Los Tenenbaums: Una familia de genios y la utilización del travelling para mostrar la reconciliación entre los personajes}

En esta película analizaremos la escena que sucede en el minuto 82 en la que Richie y Royal conversan en la azotea del hotel donde trabaja Royal acerca del por qué Richie perdió el último partido de tenis que jugó.

Richie entra a la azotea, cierra la puerta y hay un paneo horizontal hasta donde se encuentra Royal, Richie entra al encuadre y Royal le pregunta si es Margot Tenenbaum la chica de la cual él está enamorado, su hijo le contesta que sí. Comienza el travelling de acompañamiento (F4) mientras estos dos personajes caminan. Royal le pregunta a su hijo desde cuándo es que está enamorado de Margot, él le contesta que desde siempre, Royal le pregunta nuevamente si ella lo sabe y cómo se siente al respecto, Richie le contesta que sí y que cree que se siente confusa. Royal le dice que lo entiende y que probablemente eso sea ilegal, Richie responde que no cree que lo sea porque no existen lazos de sangre entre él y Margot, a lo que Royal le dice: "Es verdad. Está mal visto, ¿pero qué no lo está hoy en día?”.

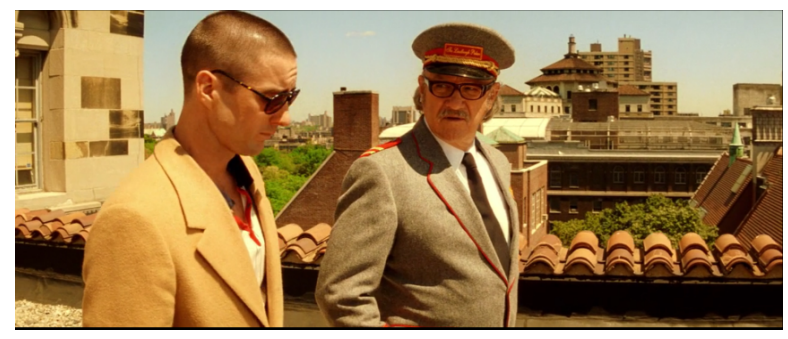

F4: Travelling de acompañamiento.

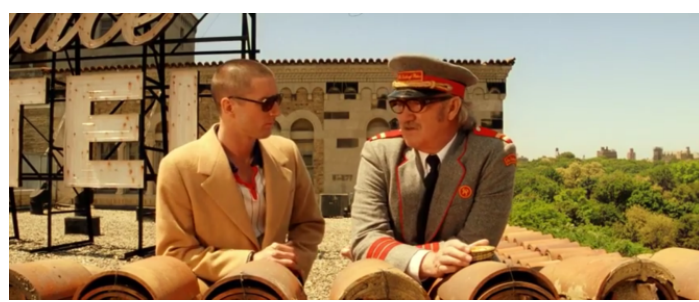

F5: Primer travelling de acercamiento.

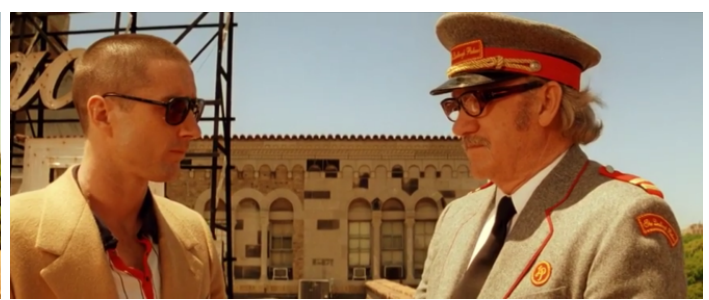

F6: Segundo travelling de acercamiento.

Royal y Richie llegan hasta la esquina de la azotea y hay un travelling de acercamiento (F5). En un plano conjunto, Royal le dice a su hijo que tal vez su relación con Margot funcione, que nadie sabe lo que va a pasar. Luego hay un contraplano de Royal en el que este comenta que no le haga caso, que 
nunca ha comprendido a su madre ni a ninguno de ellos. Hay un contraplano de Richie, Royal le dice que ojalá le pudiera decir qué hacer pero que no podía, Richie le indica que está bien, Royal reconoce que no lo está, hay un plano conjunto y seguido de esto un travelling de acercamiento (F6). Royal le pregunta a su hijo si lo sigue considerando su padre, Richie le contesta que sí, Royal le expresa que ojalá tuviera más que ofrecerle en ese campo, Richie le responde: "Lo sé, papá". Los dos se miran, asienten y ven hacia abajo. Richie mira al cielo. Royal le dice que no lo culpa, que Margot es preciosa e inteligente. Después de esa conversación aparece Mordecat, el halcón de Richie a quien había dejado libre anteriormente.

Los travellings durante la conversación ayudan al espectador a acercarse hacia la confesión de los personajes, tanto de Richie, con el travelling de acompañamiento, donde el ex tenista le cuenta a su padre el amor que siente por Margot, su hermana adoptiva; así como de Royal, con los dos travellings de acercamiento, al reconocer que nunca ha logrado comprender a ningún miembro de su familia ni a él mismo, y que no puede aconsejar a su hijo debido al fracaso que tuvo en su matrimonio con la madre de Richie. Asimismo, estos dos últimos travellings sirven para mostrar la reconciliación entre padre e hijo, y termina con Royal dándole ánimos a Richie para que continúe con su relación con Margot como muestra de su evolución hacia un mejor padre, uno que se interesa por sus hijos.

\subsection{El Gran Hotel Budapest y el uso del travelling para revelar las emociones de los personajes en momentos cruciales}

En la película El Gran Hotel Budapest analizaremos una de las últimas escenas del filme, del minuto 84, en la cual el hijo de Madame D., Dimitri, está persiguiendo a Agatha, quien tiene el cuadro "Niño con manzana”, el cual valía una fortuna y era deseado por este. Dimitri y Agatha bajan del ascensor, él comienza a seguir a la chica. Agatha corre y detrás de ella va Dimitri. Los oficiales instalados en el hotel también los están buscando. Dimitri llega a los cuartos del sexto piso, hay un zoom de alejamiento, mira a los costados y hay un zoom de acercamiento, se abre el ascensor y entran Zero y Gustave H. a la escena. Dimitri saca su pistola y les empieza a 
disparar. Los soldados hospedados salen de sus cuartos y se arma una balacera. Entran el inspector Henckels y el nuevo encargado del lugar a pedir un alto al fuego cuando escuchan el grito de una mujer. Zero se da cuenta de que ha sido Agatha quien ha caído por la ventana y va en su recate, hay un travelling de acompañamiento (F7).

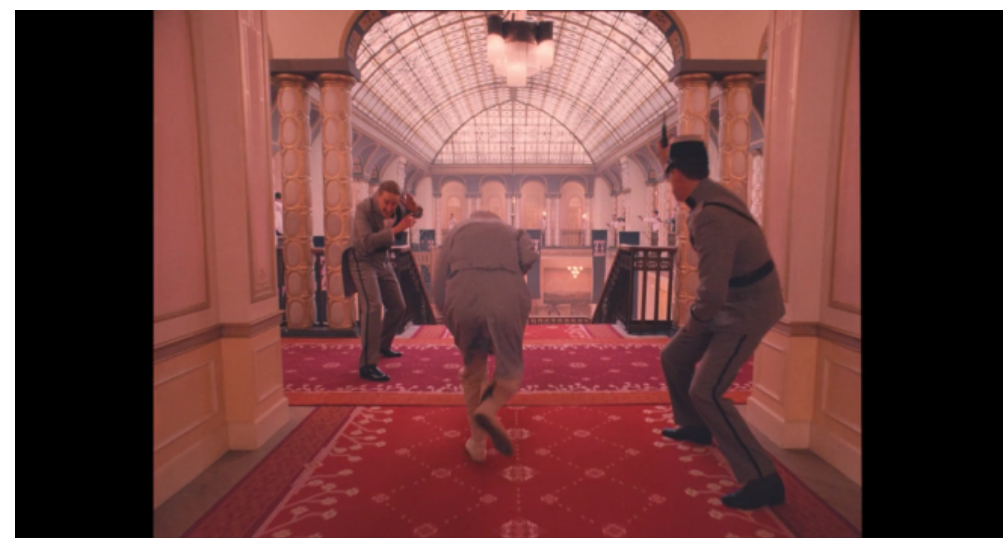

F7: Travelling de acompañamiento.

Mientras Agatha está sostenida de la baranda de la ventana, hay un zoom de acercamiento hacia el sobre que hay al reverso de la pintura, Agatha se percata de este detalle. Zero trata de forzar la puerta de la habitación para salvar a la chica, pero termina cayendo también por la ventana. Agatha y Zero se sostienen de la misma baranda, esta cede y los dos jóvenes caen dentro de un camión de Mendl's. Tras abrazarse y verificar que los dos se encuentran bien, Agatha le cuenta a Zero que hay un sobre escondido junto con la pintura.

Este travelling de acompañamiento que hemos descrito es usado por el director para darle continuidad a la acción, para que el espectador pueda sentir la desesperación de Zero por rescatar a Agatha que ha caído por la ventana. De esta manera Anderson atrae la atención del público en la historia que se desarrolla en la pantalla, nos muestra las emociones de los personajes en esos momentos, y nos prepara para lo que ocurre a continuación de ese movimiento de cámara; el descubrimiento de un hecho clave para el filme, la carta que contenía el nombre del asesino de Madame D. 
Otra escena que analizaremos es la del minuto 91. En esta escena, Zero llega al final de la historia de cómo se hizo el propietario del hotel, la cual narra a un autor durante una cena en su establecimiento.

Zero le cuenta al autor que Gustave H. murió al tratar de defenderlo del escuadrón de la muerte, que entró al tren donde ellos y Agatha viajaban, es así que Zero heredó todo. Luego de esto hay un travelling de alejamiento (F8).

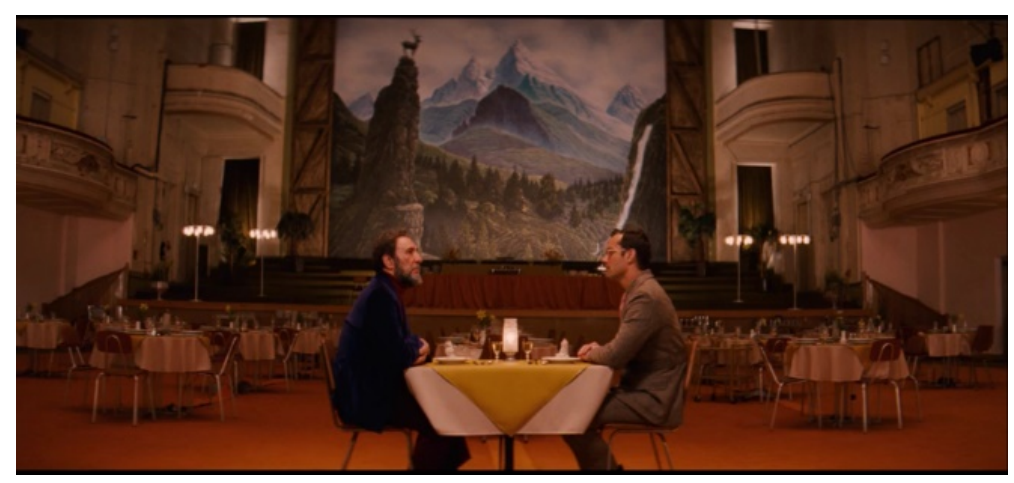

F8: Travelling de alejamiento.

Con este travelling de alejamiento, Wes Anderson resalta la tristeza que siente el protagonista luego de contar la pérdida de su amigo y mentor. La toma se abre, se amplía y se oscurece el ambiente, lo que fortalece la sensación de aflicción que siente Zero tras recordar ese episodio de su vida.

\section{Conclusión}

Los cineastas se distinguen unos de otros por la forma en que deciden emplear los recursos fílmicos existentes. El travelling es uno de estos recursos que es explotado de diferente manera debido a las opciones expresivas que puede ofrecer a las historias.

Wes Anderson es uno de los directores que hace uso del travelling como uno de los elementos del lenguaje cinematográfico para marcar su estilo propio, este movimiento de cámara es utilizado por el estadounidense para darle una mejor continuidad a sus escenas y para explorar el mundo interior y la evolución de sus personajes. 
Esto se hace evidente en los últimos treinta minutos de sus películas, en los cuales la utilización del travelling como recurso técnico distintivo en las obras de Anderson se hace más patente, ya que es usado en momentos claves de la historia, al comienzo o al final de las escenas, donde hay una gran carga emotiva debido a la transformación que ocurre en el personaje principal y en su entorno.

Este cineasta logra dar más fluidez a sus filmes mediante los travellings de acompañamiento, en los que al final de este tipo de movimiento de cámara, los personajes reflexionan y evolucionan. Asimismo, usa el travelling de acercamiento para mostrar cómo los protagonistas llegan a un autorreconocimiento luego de haber tenido una conversación donde expresaron sus verdaderos sentimientos; y el travelling de alejamiento, para reforzar la escena y que el espectador visualice este cambio final que ha tenido el personaje, al igual que sus emociones tras este momento.

Así, los travellings en los filmes de Wes Anderson ayudan a marcan el encuentro que tienen los protagonistas consigo mismos y le da continuidad a la obra tras el desenlace de la maduración sufrida por estos a lo largo de la película, ya sea al confesarse, romper con sus miedos o reconciliarse; resaltando la evolución de los personajes principales.

\section{Referencias bibliográficas}

Anderson, W. (1998). Rushmore. Estados Unidos: Touchstone Pictures.

Anderson, W. (2014). The Grand Budapest Hotel. Estados Unidos: American Empirical Pictures.

Anderson, W. (2001). The Royal Tenenbaums. Estados Unidos: Touchstone Pictures.

Aristóteles. (1974). Poética. Madrid, España: Gredos.

Arráez, R. M., y Pascual, C. (2014). La crisis de la postmodernidad: Análisis textual de los mundos sutiles de Chapero Jackson. Fotocinema. Revista Científica de Cine Y Fotografía, 8, 83-108. Recuperado de https://goo.gl/gb12ia

BBC.com. (2017). The 100 greatest comedies of all time. Recuperado de https://goo.gl/cMPAVB 
BBC.com. (2016). The 21st Century's 100 greatest films. Recuperado de https://goo.gl/DrsKJ8

Bordwell, D. (1997). On the history of film style. Massachusetts, Estados Unidos: Harvard University Press.

Bordwell, D., \& Thompson, K. (1995). El arte cinematográfico. España: Paidós Ibérica.

Bordwell, D., y Thompson, K. (2009). Film Art: An Introduction. New York, Estados Unidos: McGraw-Hill.

Boschi, E., y McNelis, T. (2012). "Same old song": on audio-visual style in the films of Wes Anderson. New Review of Film and Television Studies, 1O(1), 28-45. doi: 10.1080/17400309.2012.631174

Cortés-Selva, L. (2013). El sello del estilo visual de Dick Pope y Mike Leigh: análisis de su obra cinematográfica. Historia Y Comunicación Social, 18, 491-501. doi: 10.5209/rev_HICS.2013.v18.43983

Cortés-Selva, L., y Carmona-Martínez, M. M. (2016). El método de construcción del relato fílmico y el estilo cinematográfico de Mike Leigh: reflejo de una concepción ética y estética del mundo. $Z E R$, Revista de Estudios de Comunicación, 21(40), 109-123. doi: 10.1387/zer.15513

Ferreras, J., y Vergilio, L. (2008). A vueltas con la alfabetización visual: lenguaje y significado en las películas de Wes Anderson. Revista Científica de Información y Comunicación, 5, 248-287. Recuperado de https://goo.gl/TtCkgF

Galindo, J. M. (2015). Del autor en la historia del cine. Revisiones y nuevas vías. Zer, Revista de Estudios de Comunicación, 20(39), 49-66. doi: 10.1387/zer.15517

Herzog, M. (2014). “Does This Seem Fake?”: Wes Anderson's Kingdom of Visual Absurdity. Film Matters, 5(2), 66-67. doi: 10.1386/fm.5.2.66_1

IMDb.com. (2017). Academia Rushmore. Recuperado de https://goo.gl/r4Zrv

IMDb.com. (2017). El gran hotel Budapest. Recuperado de https://goo.gl/6CPZ4k

IMDb.com. (2017). Los Tenenbaums. Una familia de genios. Recuperado de https://goo.gl/2Uk6So

Jackson-Martín, R. (2015). Vértigo, de Alfred Hitchcock: voyeurismo y surrealidad visual. El Ojo Que Piensa, 6(11), 1-39. Recuperado de https://goo.gl/h4LJQ2

Koivumäki, M.-R. (2014). Poetic dramaturgy in Andrey Tarkovsky's Nostalgia (1983): A character without a goal? Journal of Screenwriting, 5(1), 141-155. doi: 10.1386/josc.5.1.141 
Koivumäki, M.-R. (2016). Dramaturgical Approach in Cinema-Elements of Poetic Dramaturgy in A. Tarkovsky's Films. Helsinki, Finland: Aalto ARTS Books.

López, J. (2012). De cine. Cuadernos de Documentación Multimedia, 23, 107-114. doi: 10.5209/rev_CDMU.2012.v23.41127

Martínez, E., Sánchez, L., y Segura, R. (2012). Autor, discurso y poder. El cine de vanguardia. ICONO 14. Revista de Comunicación Y Nuevas Tecnologías, 1(10), 182-197. Recuperado de https://goo.gl/Xivosj

McKee, R. (2009). El guion. Barcelona, España: Alba minus.

Mercado, G. (2011). La visión del cineasta. Madrid, España: Anaya Multimedia.

Ráez, P. (2016). El cine de Wes Anderson: aspectos de composición visual y autoría (tesis de pregrado). Universidad de Lima, Lima, Perú. Recuperado de https://goo.gl/oPULTi

Roda, S. (2015). Edward Hopper: La cinematografía de lo pictórico. Revista Latente, 13, 81-100. Recuperado de https://goo.gl/WGJuz2

Rodríguez de Austria, A. M. (2015). Aristóteles en hollywood: poética y retórica en la narrativa audiovisual. Fotocinema. Revista Científica de Cine $Y$ Fotografía, 11, 325-346. Recuperado de https://goo.gl/kmEvrg

Rodríguez, J. (2014). Construcción del espacio narrativo en el cine de John McTiernan: hacia el sello de autor. Revista de Comunicación de la SEECI, 17(35), 34-45. doi: 10.15198/seeci.2014.35·34-45

Rodríguez, J., Gonzálvez, J., y Caldevilla, D. (2016). El cine de acción de John McTiernan : autoría en la planificación y los movimientos de cámara. Revista de Ciencias Humanas y Sociales, 32(81), 12-26. Recuperado de https://goo.gl/WNKRCB

Seger, L. (1991). Cómo convertir un buen guion en un guion excelente. Madrid, España: Ediciones RIALP S.A.

Vreeland, A. V. (2015). Color Theory and Social Structure in the Films of Wes Anderson. Elon Journal of Undergraduate Research in Communications, 6(2), 35-44. Recuperado de https://goo.gl/EmsXri 